\title{
MATERNAL SOCIOECONOMIC AND NUTRITIONAL DETERMINANTS OF LOW BIRTH WEIGHT IN URBAN AREA OF BANGLADESH
}

\author{
MATIN A ${ }^{1}$, AZIMUL $\mathrm{SK}^{2}$, MATIUR AKM ${ }^{2}$, SHAMIANAZ $\mathrm{S}^{3}$, SHABNAM JH$^{4}$, ISLAM T ${ }^{5}$
}

\begin{abstract}
:
Objectives: Globally about 15.5\% of all births are born with low birth weight (LBW) and in Bangladesh, $L B W$ rate is quite high. The present study was conducted to determine the socioeconomic and nutritional factors affecting $L B W$ in urban community of Bangladesh.

Methods: This case control study was done at Department of Obstetrics \& Gynaecology of Shaheed Suhrawardy Medical College Hospital, Dhaka. Normally delivered singleton live births babies from January 2003 to January 2005 were selected purposively and after enrollment all newborns birth weight was measured. Then from the total $(N=583)$ study populations childmother pairs formed and were divided in LBW group $(n=135)$ and NBW group $(n=448)$. Data were collected regarding maternal socioeconomic and nutritional factors by interviewing the mothers and family members. Variables were analyzed to find out significant maternal factors affecting $L B W$.

Results: The LBW incidences in this study was found 23.2\%. And $51.1 \%$ of the LBW came from the mother of <20year of age group, 50\% mothers of LBW were found illiterate, socioeconomic status was significantly more poor, maternal anaemia was found significantly more common in $L B W$ and iron \& vitamin supplementation during pregnancy were found significantly less among the mothers of $L B W$ babies in comparison to NBW. Significant relationship was found between early maternal age, poor educational and socioeconomic status, anaemia, iron \& vitamin supplementation during pregnancy with $L B W$. No relationship was found between $L B W$ and maternal height but significant relationship was found with maternal weight and BMI.

Conclusion:These findings suggest that selectively targeted interventions such as delay age at first pregnancy (at $>20$ year of age), improving maternal education and nutrition, iron and vitamin supplementation can prevent $L B W$ in Bangladesh..
\end{abstract}

Key words: $L B W$ (Low Birth Weight), NBW (Normal Birth Weight), IUGR(intrauterine growth retardation).

J Dhaka Med Coll. 2008; 17(2) : 83-87.

\section{Introduction:}

Inspite of consistent efforts to improve the quality of maternal and child health, more than twenty million low birth weight (LBW) babies are born every year throughout the world. 50\% of all perinatal deaths are directly or indirectly related to $\mathrm{LBW}^{1}$. Globally about $15.5 \%$ of all births are born with $\mathrm{LBW}^{2}$, defined as a body weight of less than $2,500 \mathrm{~g}$ at birth. Ninety percent $(90 \%)$ of these LBW babies are born in developing countries. According to national low birth weight survey (2003-2004) low birth rate is quite high (36\%) in Bangladesh. Infants are born with low weight either because they are premature ( $<37$ weeks gestation at birth) and/ or because they suffered intrauterine growth retardation (IUGR). The majority of LBW infants in developing countries are $\mathrm{IUGR}^{3}$. It is generally acknowledged that the etiology of LBW is multifactorial ${ }^{4,5}$. During the fetal phase, growth depends on the nutritional condition of the mother, indicating that pregnant women should not only increase their weight but also consume essential nutrients. For many women in the developing world however, economic, social and cultural factors make it

1. Assistant Professor, Department of Paediatric Hematology \& Oncology, Dhaka Medical College, Dhaka.

2. Assistant Professor, Department of Paediatrics, Dhaka Medical College, Dhaka.

3. Lecturer, FWVTC, Azimpur, Dhaka.

4. Registrar, Department of Cardiology, BIRDEM Hospital, Dhaka.

5. Assistant Professor, Department of Paediatric Cardiology, BSMMU, Dhaka

Correspondence: Dr. A. Matin 
difficult for them to obtain the necessary food and health care, which are closely interrelated 6-8. The biological processes that affect the fetus in utero are related to the mother's physiology, including her nutrition, exercise, infections and consumption of tobacco, alcohol and other drugs. Low birth weight is strongly associated with undernutrition in mothers and about half of all IUGR in developing countries is attributable to low maternal weight, low weight gain during pregnancy and iron deficiency anaemia ${ }^{9-13}$. Mothers who are $<20$ years (teenage pregnancy) or $>35$ years old are more likely to give birth to LBW infants ${ }^{4,5,14}$. Neonatal survival depends on both gestational maturity and birth weight ${ }^{2,14,15}$. The beneficial effects of antenatal care on pregnancy outcome have been described in many observational studies over several decades ${ }^{4,13,16}$. LBW survivors demonstrate significant growth retardation, as reflected by lower body weights, heights and head circumferences, in comparison to normal weight peers 16-18. Although there is some tendency for catch up growth, the deficits persist even up till 14 years of age 19-21. The catch up is more for the preterm births in contrast to the growth retarded subjects. There is evidence of delayed skeletal growth and maturation in children aged between 6 to 10 years ${ }^{22}$. While delayed puberty has been reported in LBW children 23,24 . Earlier onset of menarche was documented in a longitudinal follow up study 19. These growth retarded adult women (stunted and underweight) are likely to give birth to LBW babies thereby perpetuating a vicious cycle through generations. The socio-economic factors are income, education, occupation affect birth weight. Other important factors are parity; inter pregnancy interval, quality and number of antenatal care along with nutrition education affect birth weight ${ }^{6,8,25-29}$. The independent effect and magnitude of each of the factors for LBW is still debatable. On the basis of available evidence this study will highlight selected independent factors of LBW in urban area of Bangladesh and that would have contributed in reducing the incidence of low birth weight in Bangladesh by evaluate the various options for action to address this major public health problem.

\section{Methodology:}

This case control study was done at Shaheed Shohrawardy Medical College Hospital, Dhaka, Bangladesh from January 2003 to January 2005. All babies with birth weight less than 2,500 gm were labeled as low birth weight (LBW) group and were compared with Normal birth weight (NBW) babies weight 2,500 gm or more as control group. From the department of Gynae \& Obstetrics samples were selected purposively following the inclusion criteria: alive baby born by normal delivery. Exclusion criteria were as follows: still born babies, baby born by caesarian section, baby born by multiple pregnancies, babies with congenital anomalies, baby with maternal history of complications (e.g eclampsia and preeclampsia, diabetes mellitus, heart disease, jaundice, chronic lung disease etc.) After enrollment in this study weight of all newborns were measured. NNC weighing scale was used to measure birth weight of the babies just after the delivery. Then the total $(\mathrm{N}=583)$ study populations were divided in two groups. All babies with birth weight less than 2,500 gm at birth were labeled as low birth weight (LBW) group $(n=135)$ and birth weight 2,500 gm or more at birth were labeled as Normal birth weight (NBW) group $(\mathrm{n}=448)$.

Informations were collected from the mothers through face to face interview by structured interview form. Questionnaire was completed within 24 hours of birth. Data were collected for age, socioeconomic status, educational status, anaemia, intake of iron and vitamins. Height, weight were measured of all mothers and Body mass index (BMI) was calculated as weight in $\mathrm{kg}$ divided by height in square meter $\left(\mathrm{Kg} / \mathrm{M}^{2}\right)$. Data were analyzed by standard statistical formula using statistical package for social science program (SPSS 11.0 version). Chi-square $\left(\chi^{2}\right)$ test was used for comparative analysis between two groups of study population. At $95 \%$ confidence limit $\mathrm{p}$ value $<0.05$ was labeled as significant. Informed consent was taken from mothers before enrolment in this study. 


\section{Results:}

After fulfilling inclusion and exclusion criteria total 583 babies were included in this study. Out of 583 babies 135 babies were found LBW and 448 babies were found NBW. The LBW incidence this study showed 23.2\%. Among total 583 babies $50.1 \%(296 / 583)$ were female and $49.9 \%(287 / 583)$ were male. In LBW group 69 were female and 66 were male besides 227 were female and 221 were male in NBW group. No relation was found between birth weight and sex of the baby. $51.1 \%(69 / 135)$ of the LBW came from the mother of $<20 y e a r$ of age group and $73 \%(327 / 448)$ of the NBW came from the mother of 20-30years age group showing association between LBW and early maternal age.

Most of the LBW 50\% (67/135) came from the mother without education but in NBW group $37 \%(165 / 448)$ came from the mother completed primary education and 53\% (238/448) from mother who completed secondary level or above. These data showed significant relationship between LBW and poor educational status. Majority of the mother came from poor economical class but it was more in LBW $79.2 \%$ $(107 / 135)$ in comparison to mother of NBW $67.4 \%(302 / 448)$ showing association between LBW and poor socioeconomic status.

\section{Table-I}

Shows maternal socio-economic factors affecting birthweight

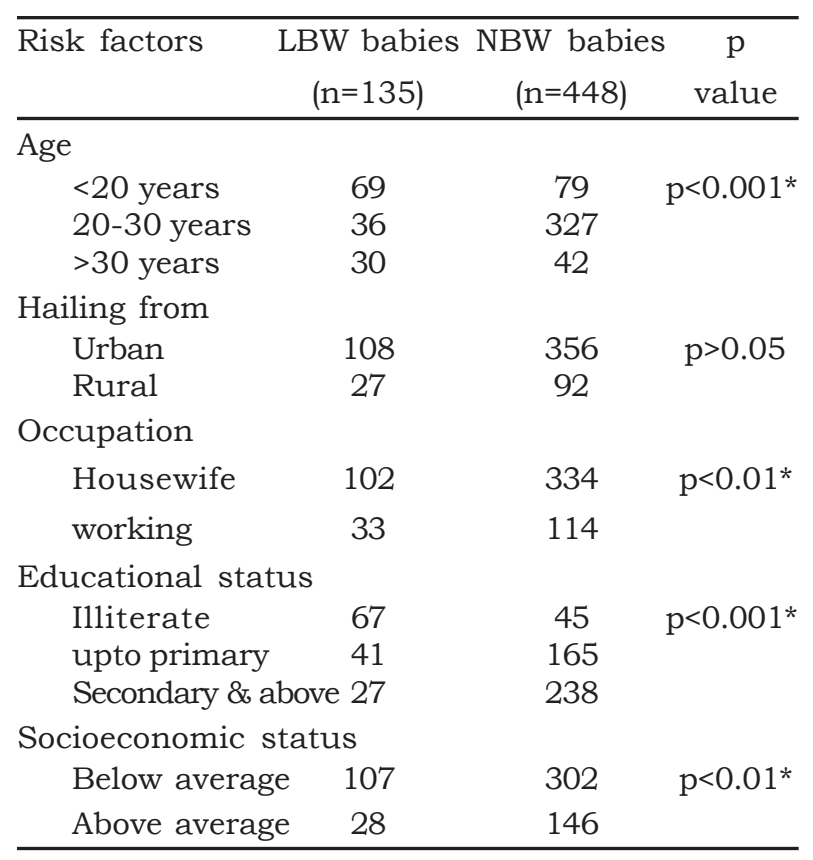

Table II

Maternal nutritional factors affecting birth weight

\begin{tabular}{|c|c|c|c|}
\hline Risk factors & $\begin{array}{l}\text { LBW babies } \\
\qquad(\mathrm{n}=135)\end{array}$ & $\begin{array}{c}\text { NBW babies } \\
(\mathrm{n}=448)\end{array}$ & $\begin{array}{c}\mathrm{p} \\
\text { value }\end{array}$ \\
\hline \multicolumn{4}{|c|}{ Maternal anaemia } \\
\hline Yes & 71 & 144 & $\mathrm{p}<0.001^{*}$ \\
\hline No & 64 & 304 & \\
\hline \multicolumn{4}{|l|}{ Maternal Height } \\
\hline$<1.55$ meter & 41 & 152 & $p>0.05$ \\
\hline$>1.55$ meter & 84 & 296 & \\
\hline \multicolumn{4}{|l|}{ Maternal Weight } \\
\hline$<55 \mathrm{Kg}$ & 53 & 133 & $\mathrm{p}<0.001^{*}$ \\
\hline$>55 \mathrm{Kg}$ & 82 & 315 & \\
\hline \multicolumn{4}{|c|}{ Maternal BMI in $\mathrm{Kg} / \mathrm{M} 2$} \\
\hline$<19$ & 41 & 59 & $\mathrm{p}<0.01^{*}$ \\
\hline$>19$ & 84 & 389 & \\
\hline
\end{tabular}

Iron $\&$ vitamin supplimentation

\begin{tabular}{lccc} 
Yes & 94 & 369 & $\mathrm{p}<0.01^{*}$ \\
No & 41 & 79 & \\
\hline
\end{tabular}

Most of the mothers (52.6\%) were found anemic who gave birth LBW and anaemia was absent among majority (67.9\%) of the mothers of NBW showing association between LBW and maternal anaenia during pregnancy. Iron \& vitamin supplementation during pregnancy were found significantly less among the mothers of LBW babies $69.6 \%(94 / 135)$ and it was more in mothers of NBW babies $82.4 \%$ (369/448).Those data showing significant positive effect of iron \& vitamin supplementation during pregnancy and negative effect of maternal anaemia on birthweight. No relationship was found between LBW and maternal height but significant relationship was found between maternal weight and birth weight. Maternal BMI showed significant positive impact on birth weight.

\section{Discussion:}

The LBW prevalence in this study was found $23.2 \%$ which was nearer to Hosain G.et al 28 where they found $24 \%$ in their study. But national low birth weight survey of Bangladesh 
(2003-2004) showed 36\% and that difference may be explained as our study was done in an urban area which does not reflect the true scenario of Bangladesh. Mean birth weight was found $2762 \mathrm{gm}$ and that was $2961 \mathrm{gm}$ by Hosain G. et al ${ }^{28}$ and 2669 gm by Deshmukh J. et al ${ }^{4}$ . Significant association was found in our study between LBW and early maternal age $(<20$ year) which is also seen by other study $5,6,28$. Finding of statistically significant relation of LBW with maternal socioeconomical status and educational level are consistent with the study of Nair NS.et $\mathrm{al}^{14}$. Maternal anaemia was found significantly more common in LBW $52.6 \%$ $(71 / 135)$ and iron \& vitamin supplementation during pregnancy were found significantly less among the mothers of LBW babies $69.6 \%$ (94/ 135 ) in comparison to NBW where it was $82.4 \%$ (369/448). Those data showed significant positive effect of iron \& vitamin supplementation during pregnancy and negative effect of maternal anaemia on birthweight, which is similar to other study 6,9,29 and differ from study of Khatun S, Rahman $\mathrm{M}^{8}$. No relationship was found between LBW and maternal height which observation was same by Hosain G. et al ${ }^{28}$. Maternal weight and BMI were found as significant risk factors for LBW that was also found by Borja JB, et $\mathrm{al}^{9}$ and Mavalankar DV et al ${ }^{12}$. There were limitation in this study as it was done in an urban area so it can not be the true representative of the country scenario. As there are several factors interacting in this phenomenon so it is not feasible to single out any particular factor affecting low birth weight. Among the various maternal risk factors like low maternal age ( $<20$ years), anaemia, maternal nutritional status and iron $\&$ vitamin supplementation during pregnancy were found to influence birth weight. Hence, it is the need of the hour to strengthen the existing maternal services at the community level to prevent and reduce LBW prevelance even in urban teritory of Bangladesh along with rural area. We have to fix strategy and have to give more attention towards awareness building to increase maternal age ( $>20$ years) and number of antenatal visit along with iron \& vitamin supplementation during pregnancy to reduce LBW in Bangladesh.

\section{Conclusion:}

This study suggests that there are several factors interplaying which lead to LBW babies even in urban area of Bangladesh. Sociodemographic factors like maternal age, educational level, economic status, nutritional status and anaemia are very important. Strategy to reduce LBW in urban area of Bangladesh along with rural community we have to focus on nutrition education, iron $\&$ vitamins supplementation during pregnancy along with discouraging teenage pregnancy.

\section{References:}

1. Gazi R, Karim F, Ali A. Low birth weight was the major predictor of infant deaths: Evidence from aprospective study in rural Bangladesh. Brac Research Annual report. 2001.

2. State of world children, UNICEF-2004, available athttp:// www.unicef.org/publications / index.html .

3. Fikree FF, Berendes HW. Risk factors for term intrauterine growth retardation: a communitybased study in Karachi. Bull World Health Org. 1994; 72: 581-7.

4. Deshmukh J, Motghare DD, Zodpey SP, Wadhva SK. low birth weight and associated maternal factors in urban area. Indian Pediatr. 1998; 35: 33-6.

5. Aurora S, Vishnu B. Habibullah S, Srinivasan S, Puri RK, Rajaram P. Maternal nutrition and birth weight. Indian $\mathrm{J}$ Mat Child Health. 1994; 5: 73-5.

6. Valero DE, Bernabé J, Soriano T, Albaladejo R, Juarranz M, Calle ME, Martínez D, DomínguezRojas V. Risk factors for low birth weight: a review. Eur J Obstet Gynecol Reprod Biol. 2004; 116: 315.

7. Kramer MS. Determinants of low birth weight. Bull World Health Org. 1987; 65: 663-737.

8. Khatun S, Rahman M. Socio-economic determinants of low birth weight in Bangladesh: a multivariate approach. BMRC Bull. 2008; 34: 81-6.

9. Borja JB, Adair LS. Assessing the net effect of young maternal age on birthweight. Am J Hum Biol. 2003;15: 733-40.

10. Khan MM. Effect of maternal anaemia on fetal parameters. J Ayub Med Coll Abbottabad. 2001; 13: $38-41$

11. Kilsztajn S, Rossbach A, Carmo MS, Sugahara GT. Prenatal care, low birth weight and prematurity Rev Saude Publica. 2003; 37: 303-10. 
12. Mavalankar DV, Gray RH, Trivedi CR. Risk factors for preterm and term low birthweight in Ahmedabad, India. Int J Epidemiol. 1992; 21: 26372 .

13. Munjanja SP, Lindmark G, Nystrom L. Randomized controlled trial of a reduced-visits program of antenatal care in Harare, Zimbabwe. Lancet. 1996; 348: 364-9.

14. Nair N, Rao RS, Chandrashekar S, Acharya D, Bhat HB. Socio-demographic and maternal determinants of low birth weight: A multivariate approach. Indian J Pediatr. 2000; 67: 9-14.

15. Naher N, Afroza S, Hossain M. Incidence of LBW in three selected communities of Bangladesh. BMRC Bull. 1998; 24: 49-54.

16. Begum R, Barua S. Birth weight in relation to other anthropometric indices and some biological and socioeconomic factors: A study in a city hospital. Bangladesh J Nutr. 1996; 9: 15-8.

17. Watanabe $\mathrm{H}$, Inoue $\mathrm{K}$, Doi $\mathrm{M}$, Matsumoto $\mathrm{M}$, Ogasawara K, Fukuoka H, Nagai Y. Risk factors for term small for gestational age infants in women with low prepregnancy body mass index. J Obstet Gynaecol Res. 2010; 36: 506-12.

18. Bhargava SK, Kumari S, Choudhury P, Ghosh S, Butani R. A longitudinal study of linear physical growth of infants with birth weight of $1500 \mathrm{~g}$ or less from birth to 6 years. Indian J Med Res. 1983; 71: $78-82$.

19. Bhargava SK, Ramji S, Srivastava U, Sachdev HP, Kapani V, Datta V, Satyanarayana L. Growth and sexual maturation of low birth weight children: A 14 year follow up. Indian Pediatr. 1995; 32: 963-70.

20. Bavedekar AR, Vaidya UV, Bhave SA, Pandit AN. Catch up growth and its determinants in low birth weightbabies: A study using $Z$ scores. Indian Pediatr 1994; 31: 1483-90.

21. Kalra SK, Sarkar P, Vatwani D, Dey NS. A longitudinal study of low birth weight babies. Indian J Pediatr. 1983; 50: 279-83.

22. Bhargava SK, Kumari S, Baijal VN, Bhan MK, Taneja S, Choudhury P. Skeletal maturation in children with birth weight of 2000 g or less. Indian J Med Res. 1980; 17: 268-72.

23. Bhargava SK, Kumari S, Baijal VN, Bhan MK, Taneja S, Choudhury P. Patterns of pubertal changes and their interrelationships in girls. Indian Pediatr. 1980; 17: 657-65.

24. Choudhari S, Kulkarni S, Pajnigar F, Pandit AN, Deshmukh S. A longitudinal follow-up of development of preterm infants. Indian Pediatr. 1991; 28: 873-80.

25. Eriksson JG, Forsen T, Tuomilehto J, Winter PD, Osmond C, Barker DJ. Catch up growth in childhood and death from coronary heart disease: Longitudinal study. BMJ. 1999; 318: 427-31.

26. Badshah S, Mason L, McKelvie K, Roger P, Paulo L. Risk factors for low birthweight in the publichospitals at Peshawar. BMC Public Health. 2008; 8: 197-9.

27. Dhar B, Mowlah G, Kabir DM. Newborn anthropometry and its relationship with maternal factors. BMRC Bull. 2003; 29: 45-58.

28. Hosain G, Chatterjee N, Afroza B, Chandra S. Factors associated with low birthweight in rural Bangladesh. J Tropic Pediatr. 2006; 52: 87-91.

29. Negi KS, Kandpal SD, Kukreti M. Epidemiological Factors Affecting Low Birth Weight. Indian J Pediatr. 2006; 8: 31-34. 